\title{
EDWARDS SYNDROME: AUTOPSY REPORT OF TWO CASES
}

\author{
Arpitha Chinnarappa Prakash ${ }^{1}$, Shivanand Sharanappa Devarmani ${ }^{2}$, Anuradha Ganesh Patil ${ }^{3}$, Sainath Karnappa Andola ${ }^{4}$ \\ 1 Post Graduate, Department of Pathology, Mahadevappa Rampure Medical College, Kalaburagi. \\ 2Professor \& Medical Superintendent, Department of Pathology, Mahadevappa Rampure Medical College, Kalaburagi. \\ 3 Professor \& HOD, Department of Pathology, Mahadevappa Rampure Medical College, Kalaburagi. \\ ${ }^{4}$ Dean \& Principal, Professor, Department of Pathology, Mahadevappa Rampure Medical College, Kalaburagi.
}

\section{ABSTRACT}

\section{BACKGROUND}

The Trisomy 18 syndrome (Edwards syndrome) is an autosomal disorder due to the presence of an extra chromosome on chromosome 18. It is a rare genetic disorder involving multiple organ systems. The recognizable features of syndrome include prenatal and postnatal growth retardation, characteristic craniofacial features, distinctive hand posture, short sternum and major malformations of heart \& kidney. Ultrasound is useful in the early antenatal detection and helps to minimize the trauma related to the termination of pregnancy at advanced gestation. Autopsy is useful in finding new anomalies and confirming antenatal ultrasonographic findings. Here we illustrate two case reports with phenotypic features, autopsy findings and brief review of literature. Genetic counselling regarding the risk of recurrence in future pregnancies is essential.

\section{KEYWORDS}

Trisomy 18, Edwards Syndrome, Autopsy.

HOW TO CITE THIS ARTICLE: Prakash AC, Devarmani SS, Patil AG, et al. Edwards syndrome: autopsy report of two cases. J. Evolution Med. Dent. Sci. 2016;5(22):1199-1202, DOI: 10.14260/jemds/2016/278

\section{INTRODUCTION}

First reported by Edward et al. and Smith et al. in 1960, Edwards syndrome is the second most common autosomal trisomy syndrome. Extra chromosome is often maternal and occurs because of meiotic nondisjunction. The live birth prevalence ranges from $1 / 3600$ to $1 / 10000$ with overall estimate in live-borns being 1/6000.(1) Female-to-male ratio is approximately 3:1.(2) In 1967, Karunakaran and Pai reported first case from India.(3) Trisomy 18 includes recognizable constellation of major and minor anomalies, predisposition to increased neonatal and infant mortality. Confirmation of the diagnosis occurs by the performance of a standard G-banded karyotype demonstrating the extra chromosome.(4) Here, we describe two cases of Edwards syndrome which were diagnosed on autopsy.

\section{MATERIALS AND METHODS}

We present two cases of Edwards syndrome diagnosed by autopsy in the year 2015 at Department of Pathology, M.R. Medical College, Kalaburagi. Autopsy was performed on both cases after obtaining written consent. The organs were fixed in $10 \%$ formalin. After thorough gross examination, representative sections were given from organs. Sections were processed routinely with paraffin embedding and stained with haematoxylin and eosin ( $\mathrm{H}$ and $\mathrm{E}$ ).

\section{RESULTS}

\section{Case 1}

A 25-year-old primigravida of non-consanguineous marriage had a normal antenatal course till 26 weeks of gestation.

Financial or Other, Competing Interest: None.

Submission 28-01-2016, Peer Review 26-02-2016,

Acceptance 04-03-2016, Published 17-03-2016.

Corresponding Author:

Dr. Arpitha Chinnarappa Prakash,

\#12, Resident's Ladies Hostel,

Basaveshwar Hospital Campus,

Kalaburagi-585105.

E-mail: arpitha.c.prakash@gmail.com

DOI: $10.14260 /$ jemds $/ 2016 / 278$
Antenatal ultrasonography at 26 weeks revealed polyhydramnios with bilaterally enlarged kidneys, absence of corpus callosum, cleft lip (Fig. 1), cleft palate and single umbilical artery. Her past medical history and family history was unremarkable. Due to the anomalous scan, couple decided to go for medical termination of pregnancy. Labour was induced and foetus (Fig. 2) weighing $1 \mathrm{~kg}$ was expelled and sent for autopsy.

On external examination, microtia (Fig. 3), malformed and low set ears, hypertelorism, flat occiput, depressed nasal bridge, cleft lip and cleft palate, short neck, polydactyly in all 4 limbs, clenched fists, single palmar crease, syndactyly in right lower limb (Fig. 3) and single umbilical artery was noted.

On internal examination, all organs were in situ. Bilateral enlarged kidneys, atrial septal defect (Fig. 4), intestine ending in a blind loop was noted. On microscopic examination, single umbilical artery was confirmed (Fig. 5). Rest of the organs were normal for gestational age.

\section{Case 2}

A 23 years old Gravida 2, Abortus 1 with second degree consanguineous marriage presented with 5 months of amenorrhoea and leaking per vagina since 2 days. First pregnancy was terminated at 5 months of gestation due to foetal anomaly (Details unknown). Emergency ultrasound revealed oligohydramnios and bilateral polycystic kidneys. Labour was induced and foetus weighing 2 kgs. was expelled and sent for autopsy.

On external examination, lemon shaped skull, depressed nose with micrognathia (Fig. 6), low set and malformed ears, short neck, meningoencephalocoele over the occiput (Fig. 6), short sternum, abdominal distension (Abdominal circumference=chest circumference), polydactyly in all 4 limbs, overriding of index over middle finger, rocker bottom feet were noted.

On internal examination, all organs were in situ. Bilateral cystic kidneys (Fig. 7) and testis like structures were 
found in lower abdomen.

On cut section, bilateral kidneys showed cysts in cortex and medulla, which were filled with clear fluid. On histology, bilateral kidneys showed cysts of variable sizes lined by flattened to cuboidal cells with no intervening glomerular structures (Fig. 8). Microscopic examination of sac-like structure over the occiput showed meningothelial cells in fibrillary background (Fig. 9). Rest of the organs were normal for gestational age.

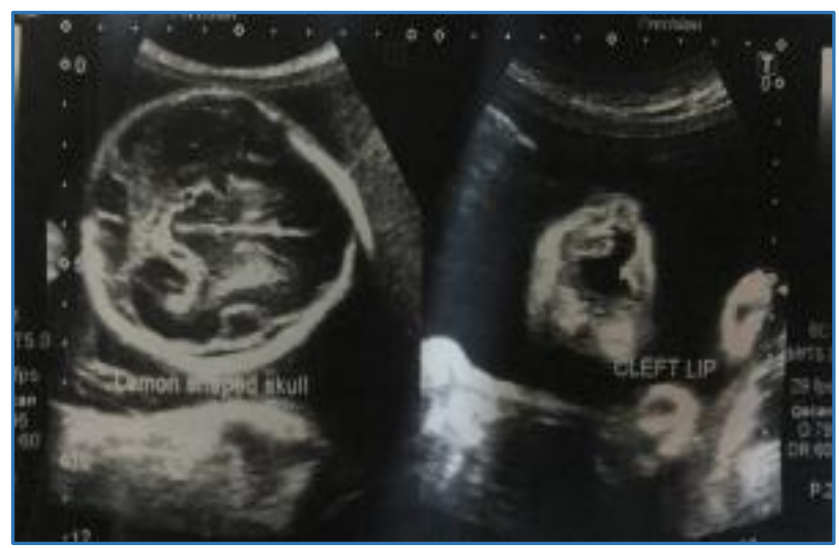

Fig. 1: 3D USG showing Lemon Shaped Skull and Cleft Lip

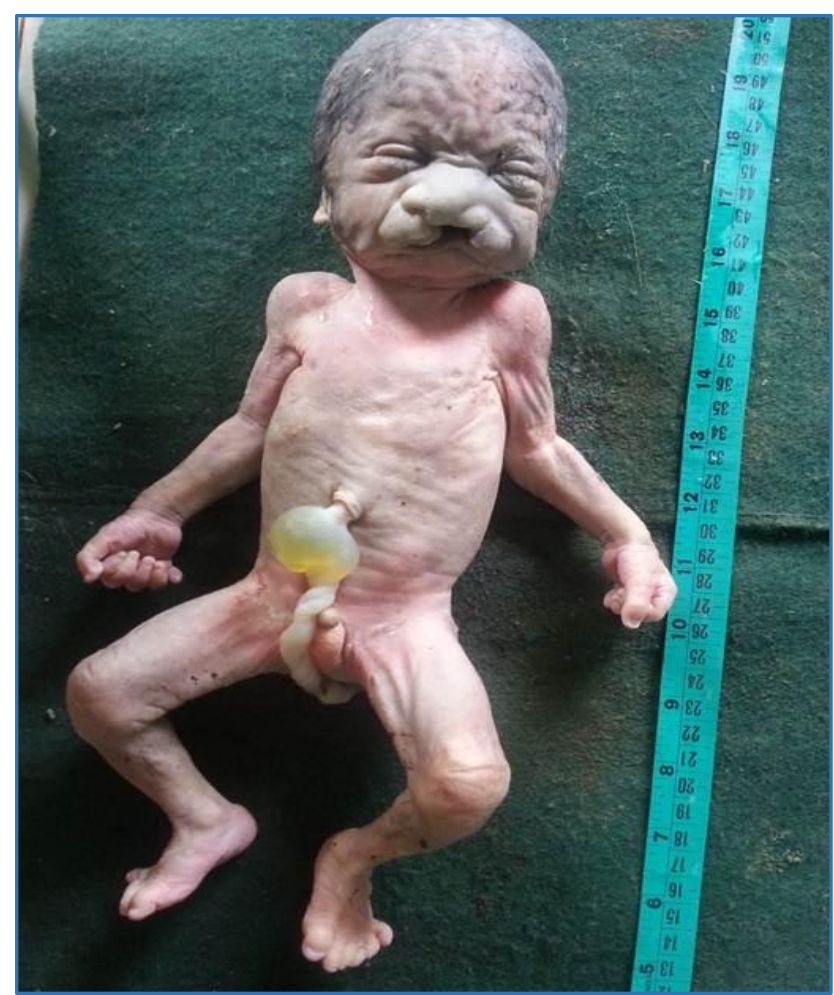

Fig. 2: External Appearance of Case 1

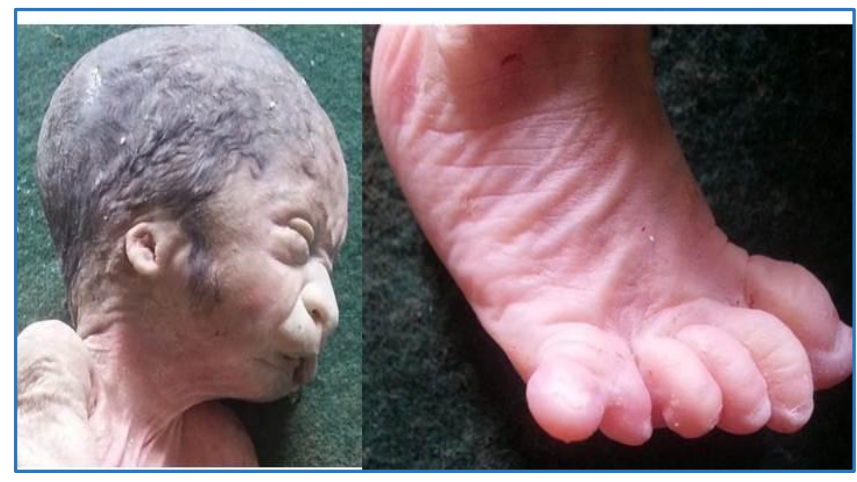

Fig. 3: Microtia and Syndactyly in Right Lower Limb

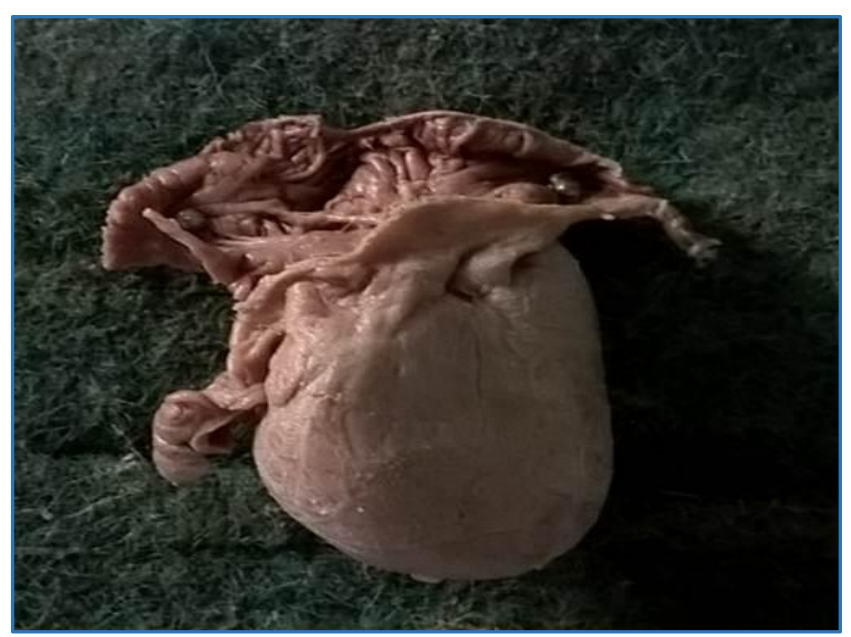

Fig. 4: Atrial Septal Defect (Single Atrium)

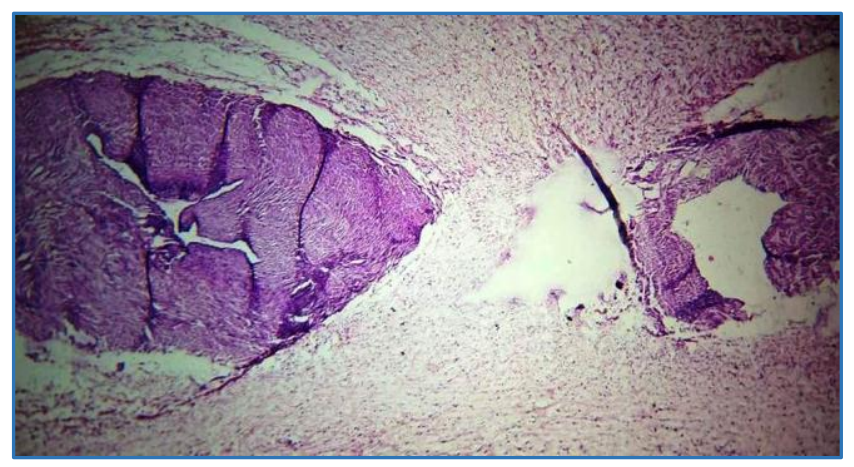

Fig. 5: Single Umbilical Artery (H\&E 10X)

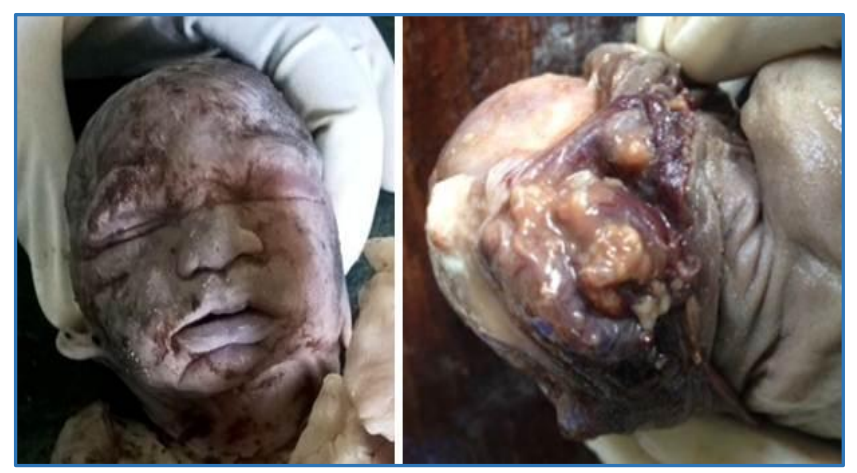

Fig. 6: Depressed Nose with Micrognathia and Meningoencephalocoele over the Occiput 


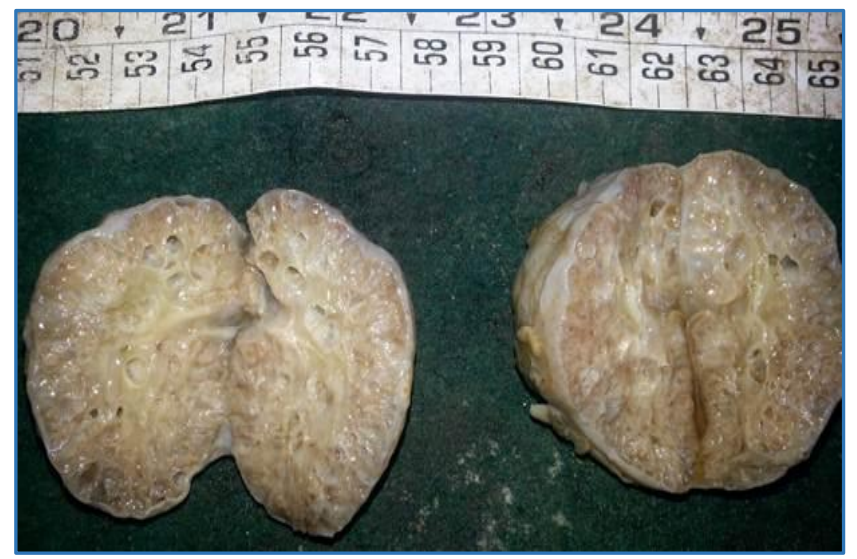

Fig. 7: Bilateral Cystic Kidneys

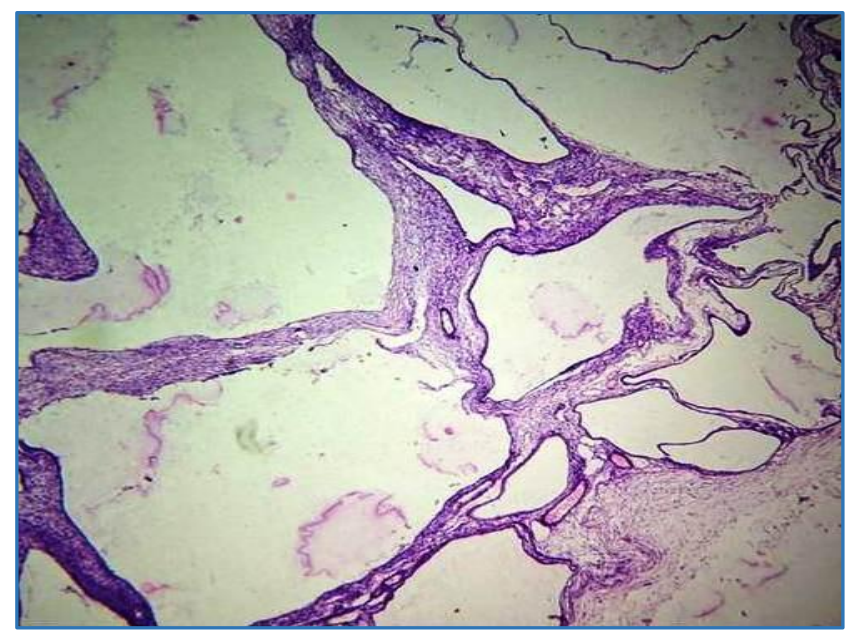

Fig. 8: Cysts of variable sizes in Kidney without Intervening Glomerulus (H\&E 40X)

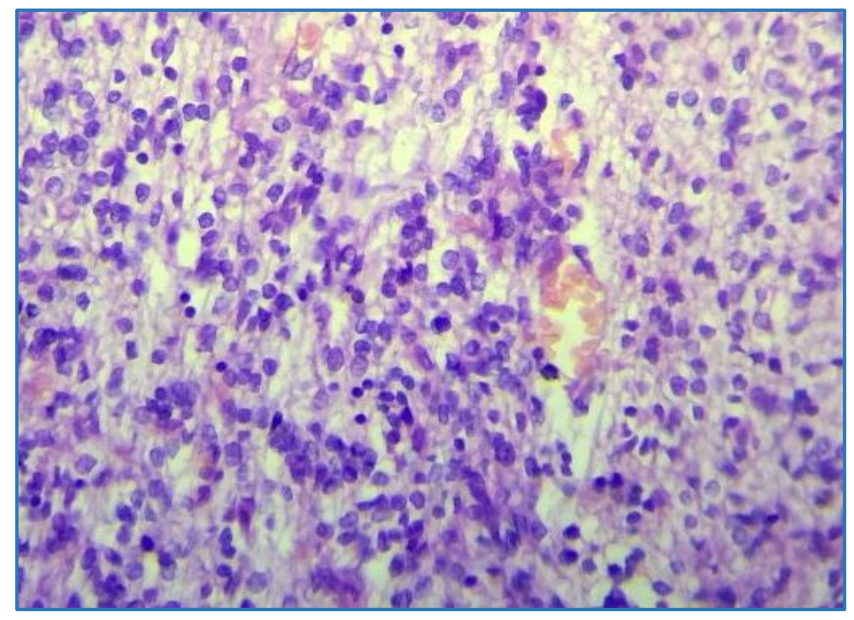

Fig. 9: Meningothelial Cells \& Fibrillary Background in Sac over the Occiput (H\&E 40X)

\section{DISCUSSION}

Edwards Syndrome was first described in 1960 by Edwards et al. and Smith et al. It is a chromosomal disorder resulting in a syndrome characterized by specific dysmorphic features and organ malformations.(5) It is a rare genetic disorder associated with multisystem involvement.(6)

Edwards syndrome phenotype results from full, mosaic or partial trisomy 18q. Complete or full trisomy 18 is the most common form. The extra chromosome is present because of meiotic nondisjunction in $80 \%$ of cases, mosaicism in $10 \%$, translocation in $5 \%$ and trisomy 18 plus sex chromosomal aneuploidy in 5\%.(2) The cause of nondisjunction is unknown. Recently, a higher prevalence of Methylene Tetrahydrofolate Reductase Gene (MTHFR) polymorphisms in mothers of trisomy 18 foetuses is reported.(1)

Most common abnormality is associated with cardiovascular system followed by extremities, urinary system, head and neck, gastrointestinal tract and genital system. Frequency of heart defects is greater than $90 \%{ }^{(7)}$ and includes ventricular septal defect, atrial septal defect and patent ductus arteriosus.(6) Most common abnormalities associated with extremities are clenched fists, overlapping of fingers, hip abduction defect, nail hypoplasia and rocker bottom feet.

Horseshoe kidney, cystic kidneys, hydronephrosis, hydroureter with posterior urethral valve are commonly found anomalies in urinary system.(6) Face has a characteristic triangular face with hypertelorism, micrognathia, low set faun ears( ${ }^{(7)}$ and rarely cleft lip and cleft palate. In gastrointestinal tract, diaphragmatic hernia, umbilical hernia and pyloric stenosis are routinely seen. Undescended testis is commonly associated with this syndrome.(6)

Most cases of trisomy 18 are prenatally diagnosed based on screening by maternal age, maternal serum marker screening or detection of sonographic abnormalities during the second and third trimester.

The levels of human chorionic gonadotropin, unconjugated oestriol and alpha-fetoprotein (triple markers) are significantly lower in pregnancies with trisomy 18 compared to normal pregnancy. The most common sonographic markers detected in the late first or early second trimester are the increased nuchal translucency thickness and the absence or hypoplasia of the nasal bone. The clinical pattern of trisomy 18 is quite well-defined and it is rarely misdiagnosed.(1) Karyotyping is required for the confirmation.

Most foetus with Edwards syndrome die during embryonic and foetal life. The median age of survival among live births varied between 2.5 and 14.5 days.(7) Survival beyond one year is rare.(2)

When prenatal or neonatal diagnosis of trisomy 18 is made, the counselling of the family should be realistic but not desolate. The parents should be prepared for both the probability of death and the possibility of living. The recurrence risk for a family with a child with complete trisomy 18 is usually stated as $1 \%$.(1) $^{(1)}$

\section{CONCLUSION}

Edwards syndrome occurs because of meiotic nondisjunction. Careful pathological examination of foetus can confirm the clinical diagnosis and help in identifying unexpected anomalies. It also assists in genetic counselling for future pregnancies. We report these cases for their rare occurrence and limited reports in literature.

\section{REFERENCES}

1. Cereda A, Carey JC. The trisomy 18 syndrome. Orphanet Journal of Rare Diseases 2012;7: 81. 
2. Barness EG, Oligny. Chromosomal abnormalities. In: Barness EG, editor. Potter's pathology of the foetus, infant and child, China: Mosby, Elsevier; 2007;2nd ed:p 236.

3. Bharucha BA, Agarwal UM, Savliwala AS, et al. Trisomy 18: Edwards syndrome, a case report of 3 cases. J Postgrad Med 1983;29:129-132.

4. Carey JC. Trisomy 18 and trisomy 13 syndromes. In: Cassidy SB, Allanson JE, editors. Management of genetic syndromes. New York: John Wiley \& Sons; 2010;3rd ed:807-823.
5. Nagamuthu EA, Neelaveni N. Edward syndrome (Trisomy 18): a case report. Annals of Biological Research 2014;5(3):67-72.

6. Arakeri S, Fatima U, Ramkumar KR, et al. A case report of Edwards syndrome and review of 152 similar cases published in various journals. Sch J App Med Sci 2014;2(2C):749-751.

7. Rosa RFM, Rosa RCM, Zen PRG, et al. Trisomy 18: review of the clinical, aetiologic, prognostic and ethical aspects. Rev Paul Paediatr 2013;31(1):111-20. 